\title{
Shadow prices, environmental stringency, and international competitiveness
}

\author{
Daan P. van Soest ${ }^{\mathrm{a}}$, John A. List ${ }^{\mathrm{b}, \mathrm{c}, *}$, Tim Jeppesen $^{\mathrm{d}}$ \\ a Department of Economics and CentER, Tilburg University, P.O. Box 90153, 5000 LE, Tilburg, \\ The Netherlands \\ ${ }^{\mathrm{b}}$ University of Maryland, 2200 Symons Hall, College Park, MD 20742-5535, USA \\ ${ }^{\mathrm{c}} N B E R$, Cambridge, MA, USA \\ ${ }^{\mathrm{d}}$ Kommunernes Revision, Oestre Stationsvej 43, 5000 Odense C, Denmark
}

Received 12 February 2004; accepted 13 February 2005

Available online 7 April 2005

\begin{abstract}
Empirical tests of the relationship between international competitiveness and the severity of environmental regulations are hampered by the lack of pollution abatement cost data for nonU.S. countries. The theory of the firm suggests that environmental stringency can be measured by the difference between a polluting input's shadow price and its market price. We make a first attempt at quantifying such a measure for two industries located in nine European OECD countries. Overall, we provide (i) a new approach to measure cross-country regulatory differences in that we use a theoretically attractive measure of industry-specific private compliance cost, and (ii) empirical estimates that are an attractive tool for researchers and policymakers who are interested in examining how economic activity is influenced by compliance costs.
\end{abstract}

(C) 2005 Elsevier B.V. All rights reserved.

JEL classification: $\mathrm{H} 73$; Q28; R38

Keywords: Cross-country environmental regulation; Interjurisdictional competition

\footnotetext{
${ }^{*}$ Corresponding author. University of Maryland, 2200 Symons Hall, College Park, MD 20742-5535, USA. Tel.: + 13010451288.

E-mail address: jlist@arec.umd.edu (J.A. List).

$U R L:$ http://www.arec.umd.edu/jlist/.
}

0014-2921/\$ - see front matter (C) 2005 Elsevier B.V. All rights reserved.

doi:10.1016/j.euroecorev.2005.02.002 
"Poorly buried drums of hazardous waste" (in Mexico) are evidence of "different levels of environmental protection around the world" that give a "competitive advantage" to nations that have "inadequate environmental protection".

U.S. Senator Max Baucus

(at the hearings of the "International Pollution Deterrence Act of 1991").

\section{Introduction}

The relationship between environmental protection and international competitiveness has been the subject of heated debate among policymakers, environmentalists, and industrial representatives. While economic theory suggests that full internalization of the negative externalities associated with economic activity (for example via environmental taxes or tradable permits) shifts the marginal cost function upward, there is a school of thought that argues that more stringent environmental policy may enhance international competitiveness (e.g., Porter and van der Linde, 1995). A typical line of argument is that apart from the productivity impacts of a cleaner environment (for example, increased quality of various inputs, such as the health of the workforce or the purity of water) and the stimulus for the production of compliance capital goods, the shock of having to meet stricter environmental regulations may induce firms to actively search for and wring out possible inefficiencies in their production processes.

A key shortcoming in the extant literature that estimates the relationship between environmental stringency and international competitiveness is the lack of consensus about the appropriate method of measuring environmental stringency. While Jaffe et al. (1995) list several indicators of competitiveness, such as net exports, share in world production, and the amount of foreign direct investment (FDI) a country receives, ${ }^{1}$ to date no convincing indicators measuring the stringency of environmental policy have been developed that allow for appropriate international comparisons. The only private cost compliance measures that we are aware of are the Pollution Abatement Cost Expenditures (PACE) data that derive compliance cost estimates by differencing current capital and operating expenditures from what these expenditures would have been absent environmental regulations. Unfortunately, time series of these data are available for the U.S. only (from the Annual Survey of Manufactures), and therefore international comparisons are frustrated. This deficiency represents a catalyst for why anecdotal evidence, such as the statement of Senator Baucus above, carries such an inordinate amount of weight in policymaking. We are of the belief that without a theoretically consistent measure of spatial environmental stringency, any debate concerning the relationship between environmental policies and international competitiveness is premature.

\footnotetext{
${ }^{1}$ These measures are not perfect, as general equilibrium adjustments will, in practice, mask the full effect of the impact of environmental stringency.
} 
This is precisely what this study offers: We make use of standard economic theory to provide a theoretically attractive measure of industry-specific private compliance cost at the country level. Besides its normative appeal, an attraction of our approach is that it is operational and can be calculated from readily available data. ${ }^{2}$ We begin with the primitive that environmental regulation imposes a constraint on the firm's use of polluting inputs (such as energy) either because it artificially reduces firm-level profitability (in the case of, for example, environmental taxes) or because it directly imposes a cap on the amount of polluting inputs used (e.g., quotas). One implication is that environmental policy drives a wedge between the firm's (or industry's) willingness to pay for an additional unit of a polluting input and the input's (undistorted) purchase price. In this case, marginal willingness to pay is equivalent to the benefits of using one additional unit that cannot be captured due to the environmental policy constraints. This value is commonly referred to as the input's shadow price, and can be estimated using data that typically are available at the country level.

The environmental stringency indicator that we propose is the difference between a polluting input's shadow price and its purchase price, and is hence firmly grounded in neoclassical theory. The indicator is able to compare the stringency of environmental policies across countries, even if they differ with respect to the type of instruments used (e.g., taxes versus quotas). The indicator also measures how actual stringency changes over time, not just changes in the (use of) environmental policy instruments themselves. Identical policies can give rise to different levels of actual stringency both over time and space: A given quota is more stringent in times of economic booms than in a recession; if prices of substitute inputs differ between countries, identical policies result in different levels of actual stringency. Our shadow price measure takes all of these considerations into account, and hence captures actual stringency rather than just differences in environmental law.

Whereas this indicator seems straightforward at first glance, determining the undistorted domestic input price is not a trivial task as general equilibrium effects may render the before-tax input prices incomparable between countries. Indeed, 'getting the prices right' is inherently closely associated with measuring environmental stringency (see Jaffe et al., 1995, p. 139). If input markets are sufficiently integrated internationally, however, the world price of the input can be viewed as the undistorted input price. In that case, intercountry comparison boils down to directly comparing marginal willingness to pay as measured by the shadow prices.

While one could consider our approach as providing an internally consistent indicator of country-level, industry-specific environmental compliance costs, it may also be complementary to the PACE data that are available for the U.S. Calculating pollution abatement costs is straightforward for end-of-pipe technologies, such as filters or scrubbers, but assessing the environmental content of integrated

\footnotetext{
${ }^{2}$ This is a rather narrow representation of our contribution, however. It is clear that both U.S. and international interest in understanding the true costs associated with environmental protection has risen tremendously in the past decade. A recent workshop at Resources for the Future highlights this increase in demand (see Burtraw et al., 2001, for a summary).
} 
technologies where input substitution may be an important factor is much more difficult. Yet, given that firms are increasingly using more comprehensive abatement strategies involving process and design changes, a more holistic measure is warranted.

This distinction is important when considering, for example, the impact on international competitiveness of policies that are aimed at achieving compliance with the Kyoto protocol. Currently the most attractive means to mitigate greenhouse gas emissions is through reduction of energy use. Therefore, whereas our indicator may be the only industry-specific cost measure available for many countries, it may be complementary to the PACE data when considering the level of stringency confronting U.S. manufacturing (Levinson, 1996).

We view our estimates as an attractive tool for researchers and policymakers who are interested in examining how economic activity is influenced by compliance costs (see, e.g., Henderson, 1996; Levinson, 1996; List and Co, 2000; List et al., 2003). Of course, the applicability of our approach is certainly not limited to this topic; it can be used to measure the importance of distortions in any market. For example, our approach can be applied to measure labor market distortions, in order to assess their impact on economic growth. ${ }^{3}$

The remainder of our paper proceeds as follows. Section 2 provides the intuition and strategy of our model. In Section 3, we discuss the advantages and disadvantages associated with our indicator of environmental stringency. We provide shadow price estimates in Section 4 and compare these measures to the conventional wisdom in the literature in Section 5. Section 6 concludes.

\section{Derivation of the shadow price indicator}

When determining their optimal input vector, firms compare the benefits of using an additional unit of each input to its cost, the purchase price. Depending on whether a production function approach or a cost function approach is taken, these marginal private benefits - the true implicit economic value for the firm, also referred to in the literature as the shadow price of the input - can be measured in terms of the input's marginal value product or as the reductions in expenditures on other inputs that can be achieved by using one additional unit of the input (while keeping output constant). In the absence of government intervention, the optimal amount of input use is intuitive: Use an input up to the point where the shadow price and the purchase price are equal.

If environmental regulations are present, however, firms are unable to equate their shadow price to the undistorted (market) input price. For example, environmental

\footnotetext{
${ }^{3}$ Another potential use of the indicators herein relates to the Millennium Challenge Account (MCA). The MCA is a 5-year, $\$ 5$ billion per year program recently begun by the Bush Administration to reward developing countries for sustainable development practices. While the MCA currently uses a number of country-level measures to determine the monetary allocation to each of the developing countries, theoretically consistent measures of environmental stringency are absent. Without a proper measure of environmental stringency, these funds may be inefficiently allocated.
} 
taxes result in a wedge between the shadow price and the undistorted input price, and cost minimization requires purchasing inputs until the shadow price is equal to the after-tax purchase price. When quotas rather than taxes are used, the difference between the shadow price and the undistorted purchase price yields the equivalent implicit tax rate, and hence makes the impact of various environmental instruments comparable.

If certain regularity conditions are met, duality theory affords us a choice of representing the technology either directly by a production function or indirectly via a cost function (Shephard, 1953). Depending on assumptions regarding market circumstances and the time horizon, these functions can be made a function of just (relative) input prices and the level of output produced (in case of full equilibrium at any instance), or also of input quantities (when instantaneous adjustment is deemed to be unrealistic). In general, however, cost functions seem slightly more attractive because we are interested in input demand responses rather than merely the production technology, and because we do not want to impose a specific production structure on the data. Whereas the amounts of variable inputs used are exogenous variables in the production function approach, they are the dependent variables in the input demand functions that can be derived from the variable cost function via Shephard's Lemma, in which prices, output, and, depending on the time horizon, quasi-fixed inputs are the arguments (e.g., Berndt, 1991).

We therefore define the shadow price of an input as the potential reduction in expenditures on other variable inputs that can be achieved by using an additional unit of the input under consideration (while maintaining the level of output). Define variable costs as $C(p, x, y, \bullet)$, where $p$ is the vector of variable input prices, $x$ is the vector of the amounts of (quasi-fixed) inputs used in production, and $y$ denotes the level of output. The shadow price of polluting input $m$, therefore, equals $Z_{m}=$ $-\partial C(p, x, y, \bullet) / \partial x_{m}$. Taking into account expenditures on polluting inputs and denoting total costs by $T C$, we derive the following relationship: $\partial T C / \partial x_{m}=$ $p_{m}-Z_{m}$, where $p_{m}$ is the (undistorted) market price of input $m$. If the polluting input's shadow price exceeds its undistorted market price $\left(Z_{m}>p_{m}\right)$, it would be advantageous for the firm or industry to increase polluting input use, resulting in a reduction of total expenditures.

The wedge $\lambda_{m}=Z_{m}-p_{m}$ can accordingly be used as an indicator of environmental policies that may restrict the firm's polluting input use either directly (in the form of quotas) or indirectly (through taxes). If the wedge is positive, the firm or industry is constrained in its usage of the input; alternatively, a negative value suggests that its use is subsidized. If, as hinted at in the introduction, the polluting input is sufficiently well traded internationally, the undistorted market price would be equal to the input's price at the world market and the relative shadow price itself would be an indicator of environmental stringency.

For our empirical implementation, we follow Morrison (1988), Morrison and Schwartz (1996), and Morrison-Paul and MacDonald (2003), and use the Generalized Leontief cost function. This particular specification has many desirable properties, such as taking into account short-run fixity of some inputs while still allowing for the analytical calculation of their long-run equilibrium levels. In 
addition, it satisfies linear homogeneity in prices and yields variable input demand functions (when applying Shephard's lemma) that are homogeneous of degree zero in prices. Furthermore, the specification is convenient as the factor demand functions are linear in the parameters, which considerably facilitates empirical estimation (Diewert, 1971). Note, however, that in the empirical analysis below, global convexity in fixed factors and concavity in price variables are not guaranteed, and thus must be verified by calculating the second derivatives of the cost function (Diewert and Wales, 1987).

There are at least two alternative cost function approaches to measuring shadow prices. First, as done by Morrison (1988) and Morrison and Schwartz (1996), the shadow price can be derived by treating the input as a quasi-fixed input, thus including $x_{m}$ in the cost function instead of $p_{m}$. This quasi-fixed input approach is based on the idea that due to environmental policy the firm (or industry) cannot freely purchase any amount of polluting inputs it chooses at their current undistorted market price. The Generalized Leontief cost function then reads as follows:

$$
\begin{aligned}
C= & y\left[\sum_{i} \sum_{j} \alpha_{i j} p_{i}^{0.5} p_{j}^{0.5}+\sum_{i} \sum_{a} \delta_{i a} p_{i} s_{a}^{0.5}+\sum_{i} p_{i} \sum_{a} \sum_{b} \gamma_{a b} s_{a}^{0.5} s_{b}^{0.5}\right] \\
& +y^{0.5}\left[\sum_{i} \sum_{v} \delta_{i v} p_{i} x_{v}^{0.5}+\sum_{i} p_{i} \sum_{a} \sum_{v} \gamma_{a v} s_{a}^{0.5} x_{v}^{0.5}\right]+\sum_{i} p_{i} \sum_{v} \sum_{f} \gamma_{v f} x_{v}^{0.5} x_{f}^{0.5},
\end{aligned}
$$

where subscripts $i$ and $j$ refer to variable inputs and subscripts $f$ and $v$ to the quasi-fixed inputs, and $s$ denotes exogenous arguments in the cost function (which are enumerated by subscripts $(a)$ and $(b)$ ), such as the state of technology (as proxied by time $t$ ) and the output level $y .{ }^{4}$ To facilitate estimation of the coefficients in (1), factor demand functions can be derived for the variable inputs using Shephard's lemma. Representing (1) by $C(p, x, y, \bullet)$, the relevant input-output ratios are

$$
\frac{x_{i}}{y}=\frac{1}{y} \frac{\partial C(p, x, y, \bullet)}{\partial p_{i}}
$$

for all variable inputs $i{ }^{5}$ Having estimated the relevant coefficients using (1) and (2), the shadow price of the quasi-fixed input $v$ can be derived as follows:

$$
\begin{aligned}
Z_{v}=-\frac{\partial C}{\partial x_{v}}= & -0.5\left[y^{0.5} \sum_{i} \delta_{i v} p_{i} x_{v}^{-0.5}+y^{0.5} \sum_{i} p_{i} \sum_{a} \gamma_{a v} s_{a}^{0.5} x_{v}^{-0.5}\right. \\
& \left.+\sum_{i} p_{i} \sum_{f} \gamma_{f v} x_{f}^{0.5} x_{v}^{-0.5}\right] .
\end{aligned}
$$

\footnotetext{
${ }^{4}$ In our empirical implementation, the variable costs functions are not only industry-specific but also country-specific; for notational convenience we suppress country indices $c$ in this section.

${ }^{5} \mathrm{We}$ use input-output ratios as they adjust for potential heteroscedasticity.
} 
The second approach, as developed by Morrison-Paul and MacDonald (2003), nests the shadow price of the input directly in the cost function by allowing it to differ from the domestic market price in the following way: $Z_{m}=p_{m}+\lambda_{m}$, where $\lambda_{m}$ is the wedge. This is a more agnostic method in the sense that the possibility of a wedge between the market and the shadow price of pollutants (indexed $m$ and $n$ ) is allowed by treating it as a variable input and directly including $Z_{m}=p_{m}+\lambda_{m}$ in the variable cost function rather than $p_{m}$, where $\lambda_{m}$ is to be determined by the data. The variable cost function to be estimated then reads as follows:

$$
\begin{aligned}
C= & y\left[\sum_{i} \sum_{j} \alpha_{i j} p_{i}^{0.5} p_{j}^{0.5}+\sum_{i} \sum_{m} \alpha_{i m} p_{i}^{0.5} Z_{m}^{0.5}+\sum_{m} \sum_{n} \alpha_{m n} Z_{m}^{0.5} Z_{n}^{0.5}\right] \\
& +y\left[\sum_{i} \sum_{a} \delta_{i a} p_{i} s_{a}^{0.5}+\sum_{m} \sum_{a} \delta_{m a} Z_{m} s_{a}^{0.5}+\sum_{i} p_{i} \sum_{a} \sum_{b} \gamma_{a b} s_{a}^{0.5} s_{b}^{0.5}\right. \\
& \left.+\sum_{m} Z_{m} \sum_{a} \sum_{b} \gamma_{a b} s_{a}^{0.5} s_{b}^{0.5}\right] \\
& +y^{0.5}\left[\sum_{i} \sum_{v} \delta_{i v} p_{i} x_{v}^{0.5}+\sum_{i} p_{i} \sum_{a} \sum_{v} \gamma_{a v} s_{a}^{0.5} x_{v}^{0.5}+\sum_{m} \sum_{v} \delta_{l v} Z_{m} x_{v}^{0.5}\right. \\
& \left.+\sum_{m} Z_{m} \sum_{a} \sum_{v} \gamma_{a v} s_{a}^{0.5} x_{v}^{0.5}\right] \\
& +\sum_{i} p_{i} \sum_{v} \sum_{f} \gamma_{v f} x_{v}^{0.5} x_{f}^{0.5}+\sum_{m} Z_{m} \sum_{v} \sum_{f} \gamma_{v f} x_{v}^{0.5} x_{f}^{0.5} .
\end{aligned}
$$

Here, subscripts $m$ and $n$ are used to denote inputs for which the shadow price may not necessarily equal market price (for example, due to environmental regulations). Note that (4) is identical to (1) if the polluting inputs are assumed to be quasi-fixed. In a theoretical sense, one would expect both approaches to yield similar results. Yet, from an empirical point of view, the direct approach is slightly preferred as additional input demand functions can be estimated, thus adding additional structure to the model and hence facilitating estimation (Morrison-Paul and MacDonald, 2003). This can be seen as follows. From (4), which can be represented as $C(p, Z, x, y, \bullet)$, the following additional functions can be derived that facilitate identification of the various coefficients:

$$
\frac{x_{i}}{y}=\frac{1}{y} \frac{\partial C(p, Z, x, y, \bullet)}{\partial p_{i}}
$$

and

$$
\frac{x_{m}}{y}=\frac{1}{y} \frac{\partial C(p, Z, x, y, \bullet)}{\partial Z_{m}} .
$$




\section{Evaluation of the shadow price indicator of environmental stringency}

The shadow price approach has several desirable properties. Most notably, because a natural interest is whether environmental standards impact international competitiveness, our indicator, which is based on private costs to firms and/or industries, is generally preferred to, for example, measures associated with the regulatory production process (such as measures of environmental quality or indices based on 'scoring' environmental laws; see Jaffe et al. (1995)). Our cost indicator may also be viewed as attractive since it provides variation not only between jurisdictions but also over time; hence, it can be used in a panel data regression framework.

Compared to other regulatory indicators available in the literature, the shadow price approach has a few additional advantages. First, the necessary data are generally available for roughly all industrialized and even developing countries (at least at higher levels of industry aggregation). Second, our indicator is industryspecific, which means that it does not necessarily suffer from the aggregation bias associated with some of the alternative compliance cost measures. Compliance cost data oftentimes are available only at high levels of industry aggregation. This constitutes a problem, as a higher level of aggregation implies a larger variance in terms of pollution intensity across the industry's subsectors. Thus, industry pollution abatement costs (per unit of output) in a jurisdiction may be low because the most pollution-intensive firms within the industry opt to locate elsewhere; low compliance costs may therefore be interpreted as reflecting high levels of stringency (Levinson and Taylor, 2001). Further, our indicator is able to reflect differences in a jurisdiction's environmental policy stance between sectors, and hence is able to improve upon existing indicators. ${ }^{6}$

Third, the shadow price yields information on the willingness to pay for an additional unit of the polluting input by measuring the cost savings for other inputs that can be achieved by marginally expanding polluting input use. Whereas our indicator is unable to cope with end-of-pipe technologies, it is well suited for dealing with integrated technologies, because unlike 'traditional' compliance cost measures it can cope with substitution possibilities between factors of production. Even the impact of increased regulation on investment can be measured by calculating its consequences for long-run capital stocks. Additionally, the indicator is able to take into account the consequences of possible general equilibrium effects. Although our indicator cannot explain changes in input prices or the input mix, these variables are used as controls in the cost function specification. For example, if increased regulatory stringency results in higher demand for non-polluting inputs, and subsequently increases their price, the shadow price adjusts to reflect this effect. The

\footnotetext{
${ }^{6}$ The necessity of having industry-specific measures of environmental stringency is emphasized by Levinson (2001), who takes into account differences in industry composition when comparing environmental stringency (as reflected by $P A C E$ data) across U.S. states. He finds that when correcting for differences in industry composition, the ordering of states in terms of stringency is affected substantially.
} 
same holds for the impact of one country's policy — for example via firm relocationon the costs of inputs in other countries.

Fourth, for empirical studies of factor location, our shadow price approach is likely to provide a more appropriate indication of the attractiveness of jurisdictions than alternative indicators that are, because of their environmental focus, by definition partial in nature. If done correctly, the actual willingness to pay of a specific industry for an additional unit of a polluting input can be determined, and hence the impact of policies other than environmental policy is taken into account. Of course, this can be interpreted as both a strength and a weakness. The weakness is that it does not yield a clean measure of environmental stringency, as it is contaminated by the influences of other governmental policies and market circumstances (including market failures). Yet its strength is that it takes into account more local considerations than merely the level of environmental policy. We believe that a proper locational analysis should take into account any policies and market failures associated with the use of polluting inputs, whether they are strictly environmental in nature or not. ${ }^{7}$ Still, theory predicts that any increase in environmental stringency would result in an increase in the shadow price of the polluting inputs. Finally, as our indicator is based on revealed behavior, it does not suffer from self-reporting bias as may be the case with the PACE survey data.

While our approach has certain appeal, we would be remiss if we did not mention the drawbacks of using shadow prices. The first major disadvantage is that environmental stringency is measured using cost data for existing firms. For a myriad of reasons, abatement costs for incumbents may be different from the overall compliance expenditures for new investment. For example, in the U.S., certain pollution control laws "grandfather" existing firms to less severe environmental standards. Alternatively, new firms may be offered tax credits and other direct and indirect subsidies by governments because of employment considerations, and thus may be compensated for differences in environmental stringency. Also, the age structure of the industry may matter (although this argument may be more important when comparing between industries within a country rather than between countries within a specific industry). We view these nuances as important, but data are difficult to obtain, and therefore, similar to Jaffe et al. (1995), we focus on compliance costs of existing firms.

The second major disadvantage of the shadow price indicator is that appropriately treating endogenous technological change is cumbersome. Apart from general equilibrium effects mentioned above, technological change may increase or decrease the optimal amount of input use (and hence the willingness to pay for an additional unit), depending on the demand elasticity for the firm's output and on the elasticity of substitution between the various production factors (and on the input's cost share).

\footnotetext{
${ }^{7}$ In the same vein, our measure will be contaminated when firms, because of reputation considerations, self-impose constraints on the use of polluting inputs, thus causing their shadow price to increase (see Jaffe et al., 1995, pp. 141-142).
} 
If technological change is exogenous (as represented by the time trend in Eq. (1)), the shadow price is able to appropriately account for both the elasticity of demand and for the elasticity of substitution between existing inputs due to the flexible nature of the specification of the Generalized Leontief cost function-see Eqs. (1) and (4). Endogeneity of technological progress, however, is a potential problem: If environmental policy results in the adoption of new production techniques that are less dependent on the use of the polluting input, the shadow price underestimates actual stringency. Indeed, our shadow price approach takes all cost information, such as information on input and output prices, substitution possibilities, and technological change as given, and cannot explain changes therein.

\section{Estimation of the shadow prices}

We operationalize our approach by estimating shadow prices of a polluting input, energy, for two industries: Food and beverages and primary metals. The choice of these industries was driven mainly by data availability, but we were careful to include one relatively pollution-intensive industry (metals) and one non-pollution-intensive sector (foods). We use input price and quantity data for nine European countries: Belgium, Denmark, Finland, France, Great Britain, Italy, the Netherlands, Sweden, and West Germany. Apart from energy, we include two other inputs in the variable cost functions: Labor and capital. The panel is unbalanced, but the longest country time series is available from 1978 to 1996. The two data sources are the IEA Energy Balances and the OECD International Sectoral Database (ISDB) (see Appendix A).

Upon experimenting with both the quasi-fixed factor model (Eqs. (1) and (2)) and the more agnostic model (Eqs. (4)-(6)), we opted for the latter, mainly because of the additional degrees of freedom resulting from the extra input demand function (6). Here we present regression results of estimating (4)-(6), where capital is the only quasi-fixed factor $(v, f=K)$, labor is assumed to be fully variable $(i, j=L)$, and the possibility of a wedge between the shadow price and the market price is allowed for in the case of energy $(m, n=E)$.

Our estimation procedure is in the spirit of previous structural modeling. However, even though estimating (4) in combination with Eqs. (5) and (6) yields additional degrees of freedom, the relatively short time period for which we have data forces us to impose additional constraints. We assume the production process is subject to long-run CRTS, which implies that the long-run output elasticities of all inputs (both the variable inputs, $x_{i}$ and $x_{m}$, and the quasi-fixed inputs, $x_{v}$ ) are equal to unity, which can be translated into setting the relevant parameters $\left(\gamma_{v y}, \gamma_{a y}, \delta_{i y}\right.$ and $\delta_{m y}$ ) equal to naught (see also Morrison, 1988). In addition, since time trends are typically statistically insignificant, we set $\delta_{i t}=\delta_{m t}=\gamma_{t t}=\gamma_{t v}=0$. We further preserve degrees of freedom by assuming that all interaction effects (for each industry) are common across countries, but allow the direct effects to be countryspecific (see Morrison, 1988).

Concerning measuring the shadow price of energy, we believe the preferred approach is to include annual country-specific wedges for energy prices $\left(\lambda_{c, t}, \forall c, t\right.$, 
where $c$ enumerates the countries in our data set). Unfortunately, due to a lack of degrees of freedom, we are left with two alternative choices: (i) capturing the wedge through a time trend, or (ii) including wedges for periods rather than for any given year. Because the former smoothes out all changes in policies into a single trend, we have chosen the latter, less restrictive, solution. We arbitrarily split the estimation period into three subperiods: 1978-1984, 1985-1989, and 1990-1996. Results are robust to alternative subperiods. The (country- and industry-specific) mark-ups for these periods are, respectively, labeled $\lambda_{c, E 78}, \lambda_{c, E 85}$, and $\lambda_{c, E 90}$.

To summarize, the basic estimation model is an industry-specific constant-returnsto-scale cost function (Eq. (4), from which (5) and (6) can be derived) in which the variable inputs' direct coefficients $\left(\alpha_{c, E E}\right.$ and $\left.\alpha_{c, L L}\right)$ are country-specific and the

Table 1

Cost functions regression results

\begin{tabular}{|c|c|c|c|}
\hline Country & Coefficient & Food and beverage industry & Primary metals industry \\
\hline Common coefficients & $\begin{array}{l}\alpha_{E L} \\
\delta_{L K} \\
\delta_{E K} \\
\gamma_{K K}\end{array}$ & $\begin{aligned} & 0.004^{* *}(30.022) \\
&-3.81 \mathrm{E}-04^{* *}(-42.610) \\
&-8.91 \mathrm{E}-04^{* *}(-9.460) \\
& 2.64 \mathrm{E}-04^{* *}(43.456)\end{aligned}$ & $\begin{aligned} & 0.003^{* *}(6.282) \\
-1.73 \mathrm{E}-04^{* *}(-8.139) & \\
-0.006^{* *}(-13.506) & 1.15 \mathrm{E}-06(0.120)\end{aligned}$ \\
\hline Belgium (BEL) & $\begin{array}{l}\alpha_{\mathrm{BEL}, L L} \\
\alpha_{\mathrm{BEL}, E E} \\
\lambda_{\mathrm{BEL}, E 78} \\
\lambda_{\mathrm{BEL}, E 85} \\
\lambda_{\mathrm{BEL}, E 90}\end{array}$ & $\begin{array}{c}0.021^{* *}(172.139) \\
0.113^{* *}(34.391) \\
-0.040^{* *}(-5.682) \\
-0.055^{* *}(-7.050) \\
-0.036^{* *}(-5.106)\end{array}$ & $\begin{aligned} 0.017^{* *} & (48.767) \\
1.017^{* *} & (57.543) \\
0.062^{* *} & (3.365) \\
-0.136^{* *} & (-5.663) \\
-0.131^{* *} & (-6.590)\end{aligned}$ \\
\hline Denmark (DEN) & $\begin{array}{l}\alpha_{\mathrm{DEN}, L L} \\
\alpha_{\mathrm{DEN}, E E} \\
\lambda_{\mathrm{DEN}, E 78} \\
\lambda_{\mathrm{DEN}, E 85} \\
\lambda_{\mathrm{DEN}, E 90}\end{array}$ & $\begin{array}{c}0.037^{* *}(81.592) \\
0.237^{* *}(38.153) \\
-0.009(-0.535) \\
-0.077^{* *}(-3.769) \\
-0.163^{* *}(-10.721)\end{array}$ & $\begin{array}{l}0.012^{* *}(3.638) \\
0.094(1.241) \\
7.638(0.988) \\
-3.172(-1.052) \\
0.706(0.835)\end{array}$ \\
\hline Finland (FIN) & $\begin{array}{l}\alpha_{\text {FIN }, L L} \\
\alpha_{\text {FIN }, E E} \\
\lambda_{\text {FIN }, E 78} \\
\lambda_{\text {FIN }, E 85} \\
\lambda_{\text {FIN }, E 90}\end{array}$ & $\begin{aligned} 0.029^{* *} & (81.991) \\
0.120^{* *} & (56.744) \\
-0.264^{* *} & (-313.98) \\
0.126^{* *} & (6.874) \\
-0.031^{* *} & (-1.664)\end{aligned}$ & $\begin{array}{c}0.020^{* *}(55.634) \\
1.334^{* *}(70.409) \\
0.022(1.826) \\
-0.021(-1.532) \\
-0.069^{* *}(-5.597)\end{array}$ \\
\hline France (FRA) & $\begin{array}{l}\alpha_{\mathrm{FRA}, L L} \\
\alpha_{\mathrm{FRA}, E E} \\
\lambda_{\mathrm{FRA}, E 78} \\
\lambda_{\mathrm{FRA}, E 85} \\
\lambda_{\mathrm{FRA}, E 90}\end{array}$ & $\begin{array}{c}0.020^{* *}(122.062) \\
0.124^{* *}(31.627) \\
-0.112^{* *}(-11.238) \\
0.146^{* *}(12.922) \\
0.074^{* *}(6.514)\end{array}$ & $\begin{array}{c}0.025^{* *}(91.823) \\
0.770^{* *}(63.113) \\
-0.107^{* *}(-18.957) \\
-0.048^{* *}(-11.547) \\
-0.057^{* *}(-13.863)\end{array}$ \\
\hline Great Britain (GBR) & $\begin{array}{l}\alpha_{\mathrm{GBR}, L L} \\
\alpha_{\mathrm{GBR}, E E} \\
\lambda_{\mathrm{GBR}, E 78} \\
\lambda_{\mathrm{GBR}, E 85} \\
\lambda_{\mathrm{GBR}, E 90}\end{array}$ & $\begin{array}{c}0.025^{* *}(369.220) \\
0.105^{* *}(39.004) \\
-0.054^{* *}(-5.300) \\
-0.050^{* *}(-5.949) \\
-0.125^{* *}(-16.220)\end{array}$ & $\begin{array}{c}0.008^{* *}(17.924) \\
0.334^{* *}(18.882) \\
-0.131^{* *}(-4.159) \\
0.007(0.377) \\
-\end{array}$ \\
\hline
\end{tabular}


Table 1 (continued)

\begin{tabular}{lccc}
\hline Country & Coefficient & Food and beverage industry & Primary metals industry \\
\hline Italy (ITA) & $\alpha_{\mathrm{ITA}, L L}$ & $0.020^{* *}(288.655)$ & $0.020^{* *}(51.218)$ \\
& $\alpha_{\mathrm{ITA}, E E}$ & $0.057^{* *}(22.614)$ & $0.759^{* *}(54.206)$ \\
& $\lambda_{\mathrm{ITA}, E 78}$ & $-0.015(-0.810)$ & $0.041(1.748)$ \\
& $\lambda_{\mathrm{ITA}, E 85}$ & $-0.119^{* *}(-6.608)$ & $-0.238^{* *}(-8.802)$ \\
& $\lambda_{\mathrm{ITA}, E 90}$ & $-0.226^{* *}(-17.562)$ & $-0.218^{* *}(-9.102)$ \\
Netherlands (NLD) & $\alpha_{\mathrm{NLD}, L L}$ & $0.022^{* *}(106.093)$ & $0.017^{* *}(65.994)$ \\
& $\alpha_{\mathrm{NLD}, E E}$ & $0.209^{* *}(81.685)$ & $0.959^{* *}(30.949)$ \\
& $\lambda_{\mathrm{NLD}, E 85}$ & $-0.034^{*}(-2.090)$ & $-0.032^{* *}(-8.020)$ \\
& $\lambda_{\mathrm{NLD}, E 90}$ & $-0.133^{* *}(-9.351)$ & $-0.017^{* *}(-4.486)$ \\
Sweden (SWE) & $\alpha_{\mathrm{SWE}, L L}$ & $0.026^{* *}(420.982)$ & $0.028^{* *}(45.291)$ \\
& $\alpha_{\mathrm{SWE}, E E}$ & $0.139^{* *}(106.841)$ & $0.976^{* *}(54.764)$ \\
& $\lambda_{\mathrm{SWE}, E 78}$ & $0.023^{* *}(6.248)$ & $0.139^{* *}(6.032)$ \\
& $\lambda_{\mathrm{SWE}, E 85}$ & $-0.035^{* *}(-9.518)$ & $-0.228^{* *}(-8.421)$ \\
& $\lambda_{\mathrm{SWE}, E 90}$ & $-0.013^{* *}(-2.982)$ & $-0.163^{* *}(-6.970)$ \\
& $\alpha_{\mathrm{WGR}, L L}$ & $0.025^{* *}(137.099)$ & $0.029^{* *}(89.017)$ \\
West Germany $(\mathrm{WGR})$ & $\alpha_{\mathrm{WGR}, E E}$ & $0.070^{* *}(12.097)$ & $0.819^{* *}(40.048)$ \\
& $\lambda_{\mathrm{WGR}, E 78}$ & $-0.260^{* *}(-17.848)$ & $-0.215^{* *}(-21.611)$ \\
& $\lambda_{\mathrm{WGR}, E 85}$ & $0.015(1.164)$ & $-0.009^{* *}(-3.231)$ \\
\hline
\end{tabular}

*Significant at the 0.05 level. **Significant at the 0.01 level.

interaction effects $\left(\alpha_{E L}, \delta_{E K}\right.$ and $\left.\delta_{L K}\right)$ and the fixed variable's coefficient $\left(\gamma_{K K}\right)$ are equivalent across countries. Furthermore, the three period-specific energy price wedges $\left(\lambda_{c, E 78}, \lambda_{c, E 85}\right.$, and $\left.\lambda_{c, E 90}\right)$ are allowed to differ between countries. Estimation is by SUR, as the equations share coefficients.

Estimation results are presented in Table 1.

Concerning the validity of the specification, we find positive signs for the variables measuring own-price effects (captured by $\alpha_{c, E E}$ and $\alpha_{c, L L}$ ), indicating that variable costs increase when the prices of either energy or labor increase. Furthermore, numerically computing the second derivatives of Eq. (4) indicates that the global convexity condition with respect to capital (the quasi-fixed input) and the global concavity condition with respect to the prices of variable inputs (energy and labor) are met.

From the wedges derived from the cost functions approach, the shadow value of energy can be calculated for both industries. In Table 2, we present country rankings based on the average shadow price of energy in each industry derived for all nine European countries.

For both industries, the ranking is more or less consistent with popular beliefs about relative stringency, with a few exceptions (such as Finland and Denmark in the case of the food and beverage industry and West Germany in the primary metals industry). In addition, the minimum and maximum values indicate the considerable variation over time, and highlight the level of overlap at the country level. 
Table 2

Country ranking based on the average shadow price of energy ${ }^{\mathrm{a}}$

\begin{tabular}{|c|c|c|c|c|c|c|c|c|c|}
\hline \multicolumn{5}{|c|}{ Food and beverages } & \multicolumn{5}{|c|}{ Primary metals } \\
\hline & & AVG (stdev) & MIN & MAX & & & AVG (stdev) & MIN & MAX \\
\hline 1 & West Germany & $0.335(0.147)$ & 0.152 & 0.521 & 1 & Denmark & $0.410(0.072)$ & 0.300 & 0.564 \\
\hline 2 & Netherlands & $0.333(0.123)$ & 0.152 & 0.521 & 2 & Sweden & $0.302(0.161)$ & 0.021 & 0.528 \\
\hline 3 & France & $0.324(0.084)$ & 0.158 & 0.435 & 3 & Finland & $0.253(0.048)$ & 0.168 & 0.334 \\
\hline 4 & Sweden & $0.303(0.046)$ & 0.230 & 0.381 & 4 & Netherlands & $0.247(0.040)$ & 0.190 & 0.328 \\
\hline 5 & Italy & $0.265(0.157)$ & 0.022 & 0.478 & 5 & Italy & $0.220(0.153)$ & 0.018 & 0.441 \\
\hline 6 & Belgium & $0.259(0.107)$ & 0.136 & 0.501 & 6 & Great Britain & $0.183(0.043)$ & 0.121 & 0.274 \\
\hline 7 & Great Britain & $0.255(0.101)$ & 0.090 & 0.421 & 7 & Belgium & $0.157(0.118)$ & 0.007 & 0.311 \\
\hline 8 & Denmark & $0.243(0.125)$ & 0.047 & 0.444 & 8 & France & $0.143(0.047)$ & 0.074 & 0.255 \\
\hline 9 & Finland & $0.133(0.062)$ & 0.011 & 0.203 & 9 & West Germany & $0.108(0.053)$ & 0.040 & 0.213 \\
\hline
\end{tabular}

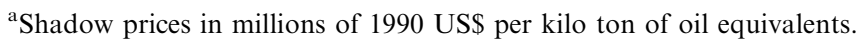

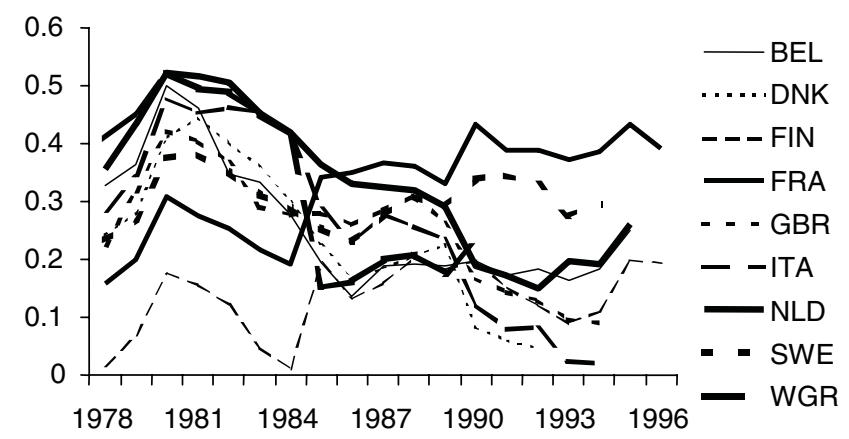

Fig. 1. Shadow prices of the food and beverage industry (in millions of 1990 U.S. dollars per kilo ton of oil equivalent).

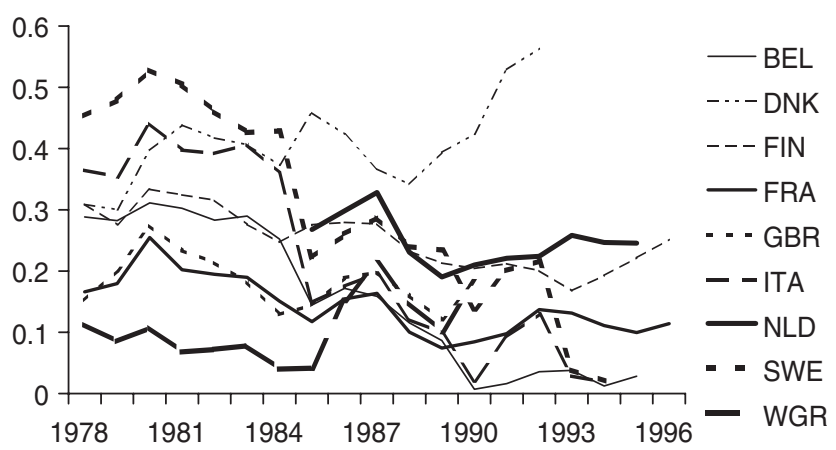

Fig. 2. Shadow prices for the primary metals industry (in millions of 1990 U.S. dollars per kilo ton of oil equivalent). 
Table 3

Correlation coefficients of shadow prices between the food and beverage and primary metals industries

\begin{tabular}{lrlr}
\hline Belgium & 0.804 & Italy & 0.915 \\
Denmark & -0.415 & Netherlands & 0.495 \\
Finland & -0.124 & Sweden & 0.236 \\
France & -0.604 & West Germany & -0.481 \\
Great Britain & 0.688 & Total & 0.072 \\
\hline
\end{tabular}

Accordingly, we report temporal shadow prices for the food and beverage and the primary metals industries in Figs. 1 and $2 .^{8}$

A quick inspection of these figures yields two observations. First, we observe a fairly high variability of environmental stringency within countries, which is unlikely to be matched by an equally high level of variability in policy design. This highlights the importance of distinguishing the environmental policy design from its actual stringency within countries over time and across space (i.e., between countries).

Second, the two figures suggest that within countries, the impact of policy differs markedly between industries. This is confirmed by calculating correlation coefficients between the shadow prices (see Table 3): While in some countries there is a fairly strong positive correlation between the shadow prices for the two industries (e.g., Belgium, Italy), we also find a negative correlation for other countries (such as France and West Germany). This negative correlation suggests that government policies are, at least to some extent, industry-specific. Industries are indeed treated differently in many countries, depending on whether they are exposed to international competition or sheltered. By imposing relatively stringent policies on the latter and relatively lax ones on the former, the governments may aim to protect both employment and the environment.

\section{The shadow price indicator compared to other measures}

In this section, we briefly summarize the relationship between our shadow price measures and other often cited measures of relative environmental efforts at the country-level. The first indicator is total revenues from environmental taxes as a share of total revenues from taxes and social contributions. These data represent a proxy for the level of environmental taxes in the member states. Data for the period 1982-1995 have been derived from the Eurostat NewCronos database, which has been supplemented by special studies on environmental taxes in all member states. The second variable we collected is public environmental $\mathrm{R} \& \mathrm{D}$ expenditures as a proportion of GDP. These data are constructed to proxy for an indicator of the

\footnotetext{
${ }^{8} \mathrm{We}$ present the country- and industry-specific shadow prices rather than the difference between these shadow prices and the undistorted market prices, as we assume the latter to be equal in all countries involved as the European energy markets are sufficiently well integrated. Hence, we avoid determining the exact level of the undistorted market price, and simply compare shadow prices directly.
} 
willingness to allocate resources to environmental protection. The data for the period 1982-1995 refer to government budget appropriations or outlays for $\mathrm{R} \& \mathrm{D}$ for the control and care of the environment, covering pollution related to air, water, soil and substrata, noise, solid waste, and radiation. The third indicator of regulatory stringency is per capita membership of environmental organizations. Eurobarometer conducts public opinion surveys twice a year. The surveys contain an identical set of questions put to representative samples (1000 persons) of the population in each member state. Occasionally the respondents are asked about their membership in environmental organizations. The fourth indicator is the lead content in gasoline. Given that lead emissions are precursors to harmful local air pollutants, a country with a relatively strict environmental policy should allow lower lead content per gallon of gasoline. For example, in 1982 Germany had a lead content measure of $0.52 \mathrm{~g}$ per gallon of gasoline, whereas Chile had a lead content of $3.12 \mathrm{~g}$ per gallon of gasoline. Data for the period 1982-1995 are available for eight countries in our data set; no information is available for Sweden.

Not surprisingly, these additional indicators are not highly correlated with one another, or with our shadow price indicator (the correlation coefficients are available upon request). The environmental tax revenue indicator is hard to interpret as a high share may reflect stringent policies, but also a low share if the environmental tax has eroded its tax base. Similar considerations apply to the interpretation of a high or low percentage of the population subscribing to environmental organizations. Public R\&D may be complementary to a stringent environmental policy, but also a substitute for one. Lead content regulations directly harm consumers as well as (part of the) transport industry, but not the two industries in our study. It may well be the case that a country actively pursues to reduce emissions of lead, whereas it is fairly lax in its regulation of its exposed industries. Indeed, the within-country differences between the shadow prices of food and beverages and basic metals suggest that we cannot explain differences in international competitiveness between sectors using one countrywide indicator.

\section{Concluding remarks}

If mobile capital responds to heterogeneous environmental standards, then a reevaluation of a good deal of public policy is necessary because some countries may be at a severe competitive disadvantage. Unfortunately, perhaps the one characteristic that highlights the current debate concerning economic growth and the environment is the reliance on anecdotal evidence. One example of this point can be found in the 1994 trade and the environment hearings, where Senator Ernest Hollings noted that "mounds of lead and...shanty homes" are evidence of "weak standards" in other countries. We find it clear that before the debate on the relative stringency of country-level environmental standards can move forward, credible theoretically consistent measures of environmental stringency must be developed. This need extends to other policy questions too, as theoretically consistent estimates 
of pollution abatement costs are critical elements of any rational effort to set or evaluate environmental policies.

In this study we make a first attempt at providing such figures by using a standard neoclassical cost function approach to estimate country-level shadow prices across various industries. In this sense, we provide (i) a new approach to measure crosscountry regulatory differences in that we use a theoretically attractive measure of industry-specific private compliance cost, and (ii) empirical estimates that are an attractive tool for researchers and policymakers who are interested in examining how economic activity is influenced by compliance costs. We leave completion of (ii) for another occasion.

\section{Acknowledgment}

We thank Catherine Co and Peter Mulder for helping with the data collection. We are grateful to the Editor and two anonymous reviewers for very thoughtful remarks. Liesl Koch, Arik Levinson, Daniel Millimet, Catherine Morrison, and Sjak Smulders provided constructive comments on an earlier draft. In addition, this paper benefited from comments raised at the Italian Conference for Environmental Economics (Acquafredda di Maratea; October 2001) and at the Second World Conference of Environmental and Resource Economists (June 2002), and from seminars at Tilburg University, Groningen University, and the University of Central Florida. Daan van Soest is grateful to the Netherlands Organization for Scientific Research (NWO) for financial support of the PRET and NWO/Novem research programs. The usual disclaimer applies.

\section{Appendix A. Data description}

Data used for the cost function estimation are derived from the IEA Energy Balances and from the OECD ISDB. Employment is measured in millions of man years; wage rates are annual wages in thousands of 1990 U.S. dollars. Capital is in billions of 1990 U.S. dollars. Energy is in millions of tons of oil equivalents, and its price is in millions of 1990 U.S. dollars per ton of oil equivalents. Output is in billions of 1990 U.S. dollars. Currency conversion has been applied by using country- and industry-specific deflators and 1990 Purchasing Power Parities.

\section{References}

Berndt, E.R., 1991. The Practice of Econometrics, Classic and Contemporary. Addison-Wesley, New York.

Burtraw, D., Krupnick, A., Morganstern, R., Pizer, W., Shih, J.-S., 2001. Workshop Report: Pollution Abatement Costs and Expenditures (PACE) Survey Design for 2000 and Beyond. RFF Working Paper, Resources for the Future, Washington, DC. 
Diewert, W.E., 1971. An application of the Shephard Duality Theorem: A generalized Leontief production function. Journal of Political Economy 79 (3), 481-507.

Diewert, W.E., Wales, T.J., 1987. Flexible functional forms and global curvature conditions. Econometrica 55 (1), 43-68.

Henderson, J.V., 1996. Effects of air quality regulation. American Economic Review 86 (4), $789-813$.

Jaffe, A.B., Peterson, S.R., Portney, P.R., Stavins, R.N., 1995. Environmental regulation and the competitiveness of U.S. Manufacturing: What does the evidence tell us? Journal of Economic Literature 33 (1), 132-163.

Levinson, A., 1996. Environmental regulations and manufacturers' location choice: Evidence from the census of manufacturers. Journal of Public Economics 62, 5-29.

Levinson, A., 2001. An industry-adjusted index of state environmental compliance costs. In: Metcalf, G., Carraro, C. (Eds.), Behavioral and Distributional Effects of Environmental Policy. University of Chicago Press, Chicago.

Levinson, A., Taylor, M.S., 2001. Trade and the environment: Unmasking the pollution haven effect. Mimeo., Georgetown University.

List, J.A., Co, C., 2000. The effects of environmental regulations on foreign direct investment. Journal of Environmental Economics and Management 40 (1), 1-20.

List, J.A., Millimet, D., Fredriksson, P., McHone, W., 2003. Effects of environmental regulations on manufacturing plant births: Evidence from a propensity score matching estimator. Review of Economics and Statistics 85, 944-952.

Morrison, C.J., 1988. Quasi-fixed inputs in U.S. and Japanese manufacturing: A generalized Leontief restricted cost function approach. Review of Economics and Statistics 70 (2), 275-287.

Morrison, C.J., Schwartz, A.E., 1996. State infrastructure and productive performance. American Economic Review 86 (5), 1095-1111.

Morrison-Paul, C.J., MacDonald, J.M., 2003. Tracing the effects of agricultural commodity prices on food processing costs. American Journal of Agricultural Economics 85 (3), 633-646.

Porter, M.E., van der Linde, C., 1995. Toward a new conception of the environment-competitiveness relationship. Journal of Economic Perspectives 9 (4), 97-118.

Shephard, R.W., 1953. Cost and Production Functions. Princeton University Press, Princeton, NJ. 